\title{
Monitoring Job Search Effort. An Evaluation Based on a Regression Discontinuity Design
}

\author{
Bart Cockx* $\quad$ Muriel Dejemeppe ${ }^{\dagger}$
}

May 31, 2012

\begin{abstract}
Since July 2004, the job search effort of long-term unemployed benefit claimants has been monitored in Belgium. We exploit the discontinuity in the treatment assignment at the age of 30 present in the first year of the reform to evaluate the effect of a notification sent at least eight months before job search is verified. Eight months after this notification and prior to the first monitoring interview, transitions to employment have increased by nearly nine percentage points compared to the counterfactual of no reform. Participation in training is raised, but not significantly, while withdrawals from the labor force are not affected.
\end{abstract}

Keywords: evaluation, monitoring job search, anticipatory effect, regression discontinuity, grouped data.

JEL-Classification: C21, J64, J65, J68, H43.

*Ghent University (SHERPPA and Faculty of Economics and Business Administration), Université catholique de Louvain (IRES), IZA (Bonn) and CESIfo (Munich). E-mail: bart.cockx@ugent.be Address: Tweekerkenstraat 2, B-9000 Gent, BELGIUM.

${ }^{\dagger}$ Université catholique de Louvain (IRES). E-mail: muriel.dejemeppe@uclouvain.be Address: Place Montesquieu 3, B-1348 Louvain-la-Neuve, BELGIUM. 


\section{Introduction}

The payment of unemployment benefits (UB) involves a trade-off between insurance and work incentives. Many economic researchers have studied how limiting the coverage of UB and the duration of benefit entitlement can restore work incentives (e.g. see Lalive et al., 2006). However, most UB schemes also provide work incentives by imposing job search requirements, amongst others, on benefit claimants. Boone et al. (2007) argue that such requirements, enforced by monitoring and sanctions, may deliver the right incentives by imposing lower costs than the aforementioned alternatives. This paper is about the impact of such a monitoring scheme introduced in the Belgian UB scheme in 2004.

In many countries monitoring of job search effort is organized along relatively standardized procedures (OECD, 2007). It starts off with a notification (often at initial registration) by which the unemployed worker is informed about the search requirements and the proofs thereof to be delivered, about the timing of the evaluations of search effort, and about the associated sanctions in the case of non-compliance. On the prescribed dates, past job search effort is evaluated on the basis of transmitted paper proofs of job applications or in faceto-face interviews. If the outcome of the evaluation is negative, a sanction in the form of a temporary and partial reduction of unemployment benefits (UB) usually follows.

Early studies ${ }^{1}$ found positive effects of monitoring on the job finding rate. However, since programs themselves often combined counseling with monitoring, they could not disentangle which of these components was responsible for such findings. A number of later contributions have succeeded in isolating the pure effects of monitoring. Klepinger et al. (1997) in the US and McVicar (2008) in Northern Ireland demonstrate that monitoring significantly increases transitions to employment ${ }^{2}$ In contrast to this evidence, Ashenfelter et al. (2005) find that tighter search requirements in the US have insignificant effects on transitions to employment and Klepinger et al. (2002) report even slightly decreasing job finding rates. This is in line with the insignificant effect of job search monitoring reported by van den Berg and van der Klaauw (2006) for the Netherlands. van den Berg and van der Klaauw (2006) argue that the result is caused by the substitution of formal by informal search, a phenomenon that would be especially relevant for well qualified workers on whom they focus in their study. Finally, Manning (2009) reports that too strict search requirements may lead UB recipients to stop claiming and to withdraw from the labor force. Petrongolo (2009) confirms this, demonstrating moreover that monitoring substantially decreases employment stability

\footnotetext{
${ }^{1}$ See Meyer (1995) for a review of US studies, Gorter and Kalb (1996) and Dolton and O'Neill (1996, 2002) for European studies.

${ }^{2}$ Borland and Tseng (2007) provide evidence of enhanced exits from unemployment, but could not identify the exit destination.
} 
and annual earnings in the long term.

In Belgium job search effort has only been monitored since 2004 and it targets only longterm unemployed workers, collecting UB for more than 13 months. Monitoring consists of face-to-face interviews in which caseworkers have a reasonable degree of discretion in the evaluation of the fulfillment of search requirements. The system is more lenient than in many other countries in that evaluations are much more spread out over time and the first negative evaluation does not lead to a monetary sanction. In addition, at the time of notification, job search requirements are not, as is usual, stated in terms of delivering proof of a minimum number of job applications, but it is rather vaguely stated that one needs to be searching for jobs on a "regular basis" and to collect written proofs of the search actions undertaken. By contrast, if imposed, sanctions are substantial. If one does not comply with the search actions stipulated at the first negative evaluation, benefits can be completely withdrawn at the subsequent interview: first temporarily during four months, but subsequently the entitlement to UB is completely halted in the case of recidivism.

In this paper we evaluate the impact of the 2004 reform in Flanders (the Dutch speaking northern region of Belgium) $]^{3}$ The analysis is based on rich administrative data, which do not only allow the impact on the job finding rate to be identified, but also on exits to training and to a residual "out of the labor force" state 4 A regression discontinuity design (RDD), resulting from the gradual phasing in of the new monitoring scheme by age group, identifies these effects under weak assumptions (Lee and Lemieux, 2010). Between July 2004 and June 2005 the job search requirements were only imposed on benefit claimants younger than 30 years on July 1, 2004. In the subsequent years, the older age groups were gradually integrated. This study exploits the discontinuity in the treatment assignment at the age of 30. Since this discontinuity disappears after a year, we can only identify the effect of monitoring job search from the moment that the assessment period starts until eight months later, before the first monitoring of past job search effort takes place. We therefore cannot study the impact of the assessments at interviews and the imposed sanctions in the case of a negative evaluation.

The outline of the article is as follows. In the next section we describe the institutional setting and the features of the new monitoring scheme. Section 3 describes the data. The estimation method is presented in Section 4 . Section 5 reports the treatment effects on various outcomes and contains a number of validity checks. A final section contains the conclusion.

\footnotetext{
${ }^{3}$ The reform was accompanied by a reinforcement of the counseling intensity in the two other regions (Wallonia and Brussels), so that the reform only identifies the pure effect of monitoring in Flanders. We refer the interested reader to Cockx and Dejemeppe (2010) for further discussion of the policy reform in Wallonia and Brussels.

${ }^{4}$ In Cockx and Dejemeppe (2010) the quality of employment in terms of starting wages and duration was also studied, but since the causal impact of monitoring on this quality could not be identified, we no longer report on this aspect.
} 


\section{Institutional Setting and Features of the New Monitoring Scheme}

\subsection{Before the 2004 Reform}

Belgium is a federal state that has decentralized certain policies to regional authorities. The payment of $\mathrm{UB}$ and the issuing of sanctions in the case of non-compliance with the rules are organized at federal level. The Public Employment Services (PES) are organized at regional level. They are in charge of counseling, job search assistance, intermediation services and training of unemployed and employed workers.

In Belgium a worker is entitled to UB in two instances: (i) after graduation from school conditional on a waiting period of nine months; (ii) after involuntary dismissal from a sufficiently long-lasting job. In contrast to many other countries there is no time limit on the payment of UB 5 School-leavers are entitled to flat rate benefits while dismissed workers earn a gross replacement rate ranging between $40 \%$ and $60 \%$ of past earnings, which is bracketed by a floor and a cap. The benefit level depends on household type (head of household, cohabitant or single) and on unemployment duration for dismissed singles and cohabitants.

Sanctions could be imposed for not complying with administrative rules: (i) making a false declaration (e.g. with regard to the household type or an undeclared employment relationship) or (ii) being unavailable for the labor market (not registered as a job searcher at the regional PES, not turning up at an appointment in the PES or UB agency, turning down a 'suitable' job offer or refusing job search assistance or participation in training offered by the regional PES, etc.). Before the reform in 2004, roughly $80 \%$ of the monitoring reports regarding availability concerned not turning up at an appointment. Job search was not monitored at that time 6

Job seekers may on their own initiative make use of the services provided by the regional PES free of charge. In addition, before the 2004 reform the PES in Flanders followed up all registered job seekers systematically. Inspired by the first European guidelines for employment 7 job seekers were required to attend a meeting with a counselor a number of months (9 months for those older than 25) after the initial registration. Depending on the outcome of this meeting, an action plan was drawn up and followed up. Non-compliance with action plans could be sanctioned. However, the imposed actions did not consist of job search, but of participation in counseling and training programs, and of responding to job offer referrals.

\footnotetext{
${ }^{5}$ There was an exception for cohabitants living with a partner earning a sufficiently high income (Cockx and Ries, 2004). However, this scheme was abolished with the 2004 reform.

${ }^{6}$ Note that at counseling interviews job search strategies could be discussed, but counselors did not monitor job search effort and if the unemployed person did not follow up the job search advice of the counselor, she would not be sanctioned.

${ }^{7}$ This refers to the guidelines decided at the meeting of the European Summit in Luxembourg in 1997 stating that all unemployed workers should be counseled and appropriately activated not later than six or 12 months after the start of their unemployment spell, respectively for those younger or older than 25 years.
} 


\subsection{The 2004 Reform}

The monitoring scheme was gradually phased in by age group. Between July 2004 and June 2005 only unemployed workers younger than 30 (on July 1) were involved. In the following year those younger than 40 were included and between July 2006 and June 2007 those younger than 50 . Those older than 50 years are not targeted by the scheme. The analysis in this paper exploits the discontinuity in the treatment assignment at 30 years in the first year of the reform.

Figure 1: Timing of the Monitoring Procedure in the Case of Negative Evaluation.

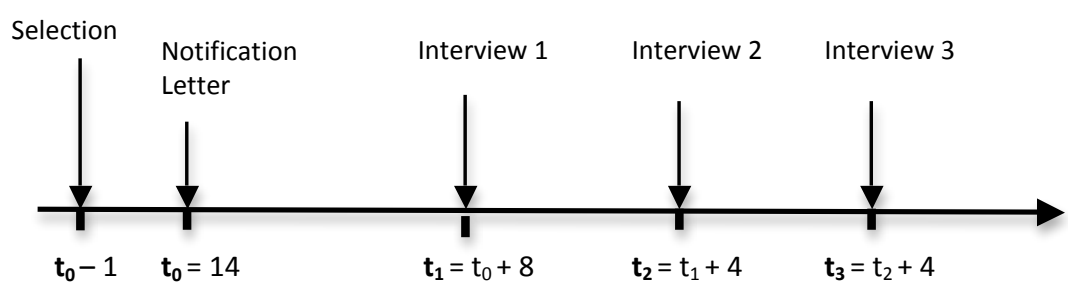

The monitoring procedure consists of several steps: a notification and up to three faceto-face interviews. Figure 1 summarizes the timing in the case of negative evaluation. In the case of positive evaluation at any of the interviews, a new sequence of interviews is scheduled: 16 months later after the first interview and 12 months later otherwise.

First, the administration selects individuals who have been entitled to UB for 13 months or more. Roughly one month later (see Section 3.1. for more details) a notification is sent by mail. It states that the person concerned is required to actively search for a job and to participate in any action proposed by the regional PES. Some examples of search methods are provided (copies of letters of application, registration in temporary help agencies, participation in selection procedures, etc.) and it is clearly stated that she should collect written proofs of the search actions undertaken. No quantitative target of the minimum number of job applications is, however, set. The letter states that the person will be invited to the UB office to evaluate job search activities retrospectively and that this first interview will take place at least eight months later. The letter also mentions that the person should contact the regional PES if she has not been individually counseled before. This is less relevant for the unemployed in Flanders, since, as mentioned in Section 2.1, in this region all the unemployed aged over 25 are already systematically counseled after nine months.

The monitoring interviews last approximately half an hour. If search effort at the first and second interview is deemed insufficient an individual action plan is drawn up. This action plan is evaluated four months later. It states more precise quantitative targets with respect to the number and type of job search activities to be fulfilled, but there is substantial 
heterogeneity in these plans, since caseworkers may tailor them to individual needs. In addition, caseworkers have a reasonable degree of discretion in assessing the achievement of these targets.

In the case of non-compliance benefit sanctions are imposed progressively: (i) No benefit sanction after a first negative evaluation; (ii) Complete withdrawal of the entitlement to UB for four months after a second negative evaluation; (iii) Complete withdrawal of UB until a new entitlement is established after a third negative evaluation. New entitlement to UB requires proving a spell of full-time employment that lasts at least 12 months without any interruption. Sanctioned individuals can apply for lower means-tested social assistance benefits.

Overall, on the one hand this description seems to suggest that monitoring job search effort is more lenient than in other OECD countries. Job search requirements are imprecise and no benefit sanction is imposed in the case of non-compliance at the first interview. In addition, the frequency of monitoring contrasts quite starkly with that in many other countries: half of the OECD countries require reporting of job search (in most cases) every two weeks or at least monthly (OECD, 2007). On the other hand, beyond the first interview, the sanctions in the case of non-compliance seem generally tougher in Belgium than elsewhere. For instance, in the Netherlands, a typical punishment for insufficient job search is a $10 \%$ reduction of unemployment benefits for a period of two months (van den Berg and van der Klaauw, 2006). Moreover, for those still unemployed at the interviews, the probability of a negative evaluation is high: $44 \%$ at the first interview, $48 \%$ at the second and $60 \%$ at the third ${ }^{8}$ Even if these figures are selective in that they are calculated relative to populations who exerted relatively little search effort (since they would otherwise no longer be unemployed), they are relevant, since they indicate that the sanction rate is high in the case of non-compliance and that the threat of a sanction is therefore credible.

\section{The Data}

We exploit administrative data from several sources: (i) the federal UB agency for monthly information on UB claims, the monitoring procedure and re-entry into regular education; (ii) the regional PES for participation in training and job search assistance provided to the unemployed; (iii) the Crossroads Bank for Social Security which matches the aforementioned information to records of all federal Social Security institutions. These matched data allowed us to construct monthly indicators of employment (including self-employment), training (which includes returns to regular education), and a residual state "out of the labor force", which is defined as not being employed, neither an UB claimant nor in training. This information is available for all sampled individuals from January 2001 until the end of 2006.

\footnotetext{
${ }^{8}$ These are average rates among those aged under 30 in the period 2004-8.
} 


\subsection{Sample Selection Criteria}

In 2004 the notification in the new monitoring procedure was sent only to individuals who were younger than 30 years old on the 1 July 2004. Our sample contains individuals living in Flanders who were at that moment aged 25 years or over, but under 35. For reasons of confidentiality, the age information was grouped in monthly intervals.

Notifications are sent on a monthly basis. In order to determine the population to whom they are sent in a particular month (e.g. in July), the administration selects individuals who have been unemployed 13 months or more according to the last available updated information, i.e. at the end of the second month prior to the month of dispatch of the notification (on May 31 in the example). This delays the moment when the unemployed are notified up to one month: if the person remains unemployed without any interruption since this last update, the notification is sent after an effective unemployment duration of more than 14

months. However, since the duration counter ${ }^{9}$ is reset to zero only if the worker has been 12 months full time employed within the preceding 15 months, unemployment duration may be shorter (but not less than 13 months) for individuals who have temporarily interrupted their unemployment spell since selection.

The sample contains all individuals entitled to UB because they were dismissed 10 All sampled individuals claimed exactly 13 months at the end of each month between May and August 2004 and satisfied all other requirements to be sent a notification, except the age requirement for those older than 30 . Workers who were entitled for more than 13 months to UB at sample selection were not retained, because the assignment of this group was not discontinuous according to age (see Cockx and Dejemeppe 2007 for more details). Those notified after October 2004 were not considered, since we aim to measure the impact of notification up to eight months later: In July 2005 the group aged over 30 years starts being notified.

Since individuals in this sample may have found a job between the selection date and the receipt of the notification, we can use it to check whether claimants anticipate the notification (see Section 5.1.3). However, in the main analysis we are interested in the effect of monitoring for those claimants who were unemployed at the moment that they were notified. We therefore exclude those individuals who between the selection date and the notification stopped claiming UB. To estimate a placebo treatment effect (see Section 5.1.3, we also selected a sample according to exactly the same criteria one year earlier, in 2003.

In principle all sampled individuals aged under 30 should receive the notification. However, as a consequence of the discrepancy between the moment at which the sample was selected by the UB agency (April 2006) and the actual dispatch of the notification (starting in

\footnotetext{
${ }^{9}$ The duration in months is obtained by dividing the number of claimed UB days by 26, i.e. the average monthly number of payment days, and rounding down to the nearest integer.

${ }^{10}$ School-leavers were dropped from the analysis, since they are a special uncommon group at the age of 30 : Only 13 school-leavers are older than 30 .
} 
July 2004), 15\% of the sampled workers below 30 were actually not notified in the month in which they should have been according to regulations. In most cases the letter is dispatched a few months later. This is essentially a consequence of ex post rectifications in the administrative data (Cockx and Dejemeppe, 2007). As a consequence, the RDD is "fuzzy". In section 4 we briefly discuss the methodological implications.

\subsection{Descriptive Statistics}

Table 1 reports descriptive statistics of the sample retained for the main analysis. The first column refers to the sample of unemployed workers between 25 and 29 years old (the "treated") and the second to those aged between 30 and 34 (the "controls"). The data provide

Table 1: Descriptive Statistics by Age Group

\begin{tabular}{|c|c|c|}
\hline & 25-29 years & 30-34 years \\
\hline Number of individuals & 1,088 & 1,152 \\
\hline \multicolumn{3}{|l|}{ Month of (potential) notification } \\
\hline July & $27.2 \%$ & $28.8 \%$ \\
\hline August & $25.6 \%$ & $23.7 \%$ \\
\hline September & $24.5 \%$ & $24.6 \%$ \\
\hline October & $22.6 \%$ & $22.9 \%$ \\
\hline \multicolumn{3}{|l|}{ Age } \\
\hline mean age in years on July 1, 2004 & 27.1 & 32.1 \\
\hline (standard deviation) & (1.4) & (1.4) \\
\hline \multicolumn{3}{|l|}{ Sex } \\
\hline women & $53.0 \%$ & $53.1 \%$ \\
\hline \multicolumn{3}{|l|}{ Nationality } \\
\hline Belgian & $88.8 \%$ & $86.6 \%$ \\
\hline EU15 (excluding Belgian) & $3.1 \%$ & $5.1 \%$ \\
\hline others & $8.1 \%$ & $8.3 \%$ \\
\hline \multicolumn{3}{|l|}{ Schooling level } \\
\hline primary & $17.1 \%$ & $22.6 \%$ \\
\hline lower secondary & $22.2 \%$ & $17.8 \%$ \\
\hline upper secondary & $47.4 \%$ & $41.7 \%$ \\
\hline higher education & $13.1 \%$ & $17.7 \%$ \\
\hline other studies & $0.1 \%$ & $0.3 \%$ \\
\hline \multicolumn{3}{|l|}{ Category of insured unemployment ${ }^{(a)}$} \\
\hline head of household & $16.6 \%$ & $23.4 \%$ \\
\hline single & $24.5 \%$ & $22.7 \%$ \\
\hline cohabitant & $58.8 \%$ & $53.9 \%$ \\
\hline Recent participation in training ${ }^{(a)(b)}$ & $17.7 \%$ & $19.3 \%$ \\
\hline Recent work experience ${ }^{(a)(b)}$ & $50.5 \%$ & $42.6 \%$ \\
\hline mean number of days in employment & 76.1 & 80.3 \\
\hline (standard deviation) & $(67.6)$ & $(70.8)$ \\
\hline Mean unemployment rate ${ }^{(c)}$ by district of living (standard deviation) & $\begin{array}{l}8.3 \% \\
(1.8)\end{array}$ & $\begin{array}{l}8.2 \% \\
(1.8)\end{array}$ \\
\hline
\end{tabular}

\footnotetext{
(a) At the sampling date, i.e. 1 month prior to the (potential) notification.

(b) During the year before the sampling date.

(c) The ratio of the number of benefit claimants available for the labor market and the number of workers insured against unemployment, by district of living on May 31.
}

information on the following characteristics of the unemployed workers: the starting date of the observation window corresponding to (potential) dispatch of the notification letter (July, August, September or October 2004), the age reported in years (but measured in months) on the 1 July 2004, the gender, the nationality, the level of education, the household-type 
determining the UB level (head of household, single or cohabitant), an indicator of recent participation in training (including a return to regular education and job search assistance) and of recent employment experience, both during the year before sample selection, and the unemployment rate by district of living. Time-varying variables are evaluated at the sampling date, i.e. roughly one month prior to the (potential) dispatch of the notification letter.

The composition of the population varies across age groups. The gradual increase of the educational level over time may explain why a larger share among those aged over 30 has only completed primary education. The fact that the higher educated among the long-term unemployed younger than 30 were not in employment for sufficiently long to be entitled to UB upon dismissal, ${ }^{11}$ explains why the fraction with tertiary education is also higher among the older group. The older group also contains relatively more heads of households and fewer cohabitants, since a larger fraction has left the parent's house to form a family. Note that this variation of the composition across age groups does not compromise the evaluation as long as it does not display a discontinuity at the age of 30 (see Section 5.1.3). In Section 5.1 .3 we jointly test and indeed reject the presence of such discontinuities.

Between $43 \%$ and $50 \%$ of the long-term unemployed workers have been employed during the year prior to the selection date. This apparent contradiction is related to the aforementioned administrative definition of unemployment duration which allows spell interruptions. Finally, the last line of Table 1 reports the local unemployment rates at district level. The unemployment rates reported in Table 1 are biased upwards, since employment in public administrations is excluded from the definition of the labor force, so that the denominator is underestimated. These are, however, the only available unemployment rate statistics at district level. For comparison, according to the standard ILO definition 5.5\% of the Flemish labor force was unemployed in 2004.

\subsection{The Outcome Variables}

The outcome variables are measured at the end of each month following the (potential) dispatch of notification up to the eighth month 12 Remember that we cannot consider the outcome beyond this month, as the older group starts receiving notifications and can therefore no longer serve as a control group. The benchmark outcome is a discrete indicator measuring whether any job has been found since the notification, regardless of whether any other labour market state, such as training or inactivity, has been occupied in between. More precisely, the indicator is set to one as soon as, within a month, the person concerned does not claim any UB as a full-time unemployed worker and is officially registered as a salaried or self-employed worker.

\footnotetext{
${ }^{11}$ Remember that school-leavers were not retained in the analysis.

${ }^{12}$ Note that the first monitoring interview takes place from the ninth month onwards.
} 
Three additional outcome variables are analyzed. The first is an indicator of participation in training. This indicator does not only comprise training in a strict sense, but also job search assistance and re-enrollment in regular education. The second outcome variable is an indicator of withdrawal from the labor force, defined as the residual state. Finally, we will also perform a sensitivity analysis in which we only consider direct exits to employment without any intervening transition in training or out of the labor force. This aims to investigate whether training acts as a possible pathway through which monitoring works.

\section{The Econometric Model}

The empirical analysis aims to identify the effect on the various outcome variables described in the previous section of a notification announcing that job search effort will be evaluated at least eight months later. Identification is based on the discontinuity of the treatment during the first year of the reform occurring at 30 years, as measured on July 1, 2004. RDD analysis is by now well established in the economics literature (see e.g. Imbens and Lemieux, 2008; Lee and Lemieux, 2010). The forcing variable $A_{i}$ is the age of the individual $i(i=1,2, \ldots N)$, measured in deviation from the discontinuity point at 30 years on 1 July 2004. If $D_{i} \equiv 1\left[A_{i}<\right.$ 0 ] denotes the treatment status (notification) of individual $i, \mathbf{X}_{i}$ the vector of explanatory variables and $F\left(A_{i}\right)$ is a polynomial, possibly different on either side of the discontinuity point (a "spline"), then the following linear regression equation identifies the treatment effect $\beta_{k}$ in the $k^{t h}$ month $(k=1,2, \ldots 8)$ after (potential) dispatch of the notification:

$$
Y_{i k}=\alpha_{k}+\beta_{k} D_{i}+F\left(A_{i}\right)+\mathbf{X}_{i} \gamma+U_{i k}
$$

where $Y_{i k}$ is the outcome variable of interest for individual $i$ at the end of the $k^{\text {th }}$ month and $U_{i k}$ denotes the error term. We use cluster-robust standard errors at the individual level to take both heteroskedasticity and the correlation of across time $k$ into account.

In Section 3.1 we mentioned that the RDD is "fuzzy". Observe that the fuzzy design is particular in that the treatment is only available at one side of the discontinuity threshold: No individual older than 30 is assigned to the treatment. Battistin and Rettore (2008) show that in this case identification assumptions of the sharp design are sufficient to identify the average treatment effect of the treated (ATT) at the discontinuity point. Since the fraction of those treated is never lower than $85 \%$, ignoring the fuzzy nature of the RDD only leads to a minor under estimation of the treatment effect. In the presentation of the empirical results we report the two-stage least squares (2SLS) estimator for the preferred specifications of the four aforementioned outcome variables. We choose in the first step the same degree of the polynomial spline as in the second step and $D_{i}$ acts as an "instrumental variable". For simplicity, the sensitivity and validity analysis is based on ordinary least squares (OLS), i.e. on the "intention-to-treat" effects. 


\section{The Empirical Findings}

\subsection{The Effect of the Notification on the Job Finding Rate}

We first present the findings for a benchmark model. Subsequently, we perform a sensitivity analysis and test the validity of the RDD.

\subsubsection{The Benchmark Findings}

Figure 2 displays descriptive evidence of the effect of monitoring eight months after dispatch of the notification. The average transition rate since notification in bins with a bandwidth of 10 months is plotted in a window of five years on either side of the cutoff point of 30 years (= 360 months). A narrower bandwidth would make graphical evidence too noisy ${ }^{13}$

Figure 2: Discontinuity of the Job Finding Rate Eight Months after Notification

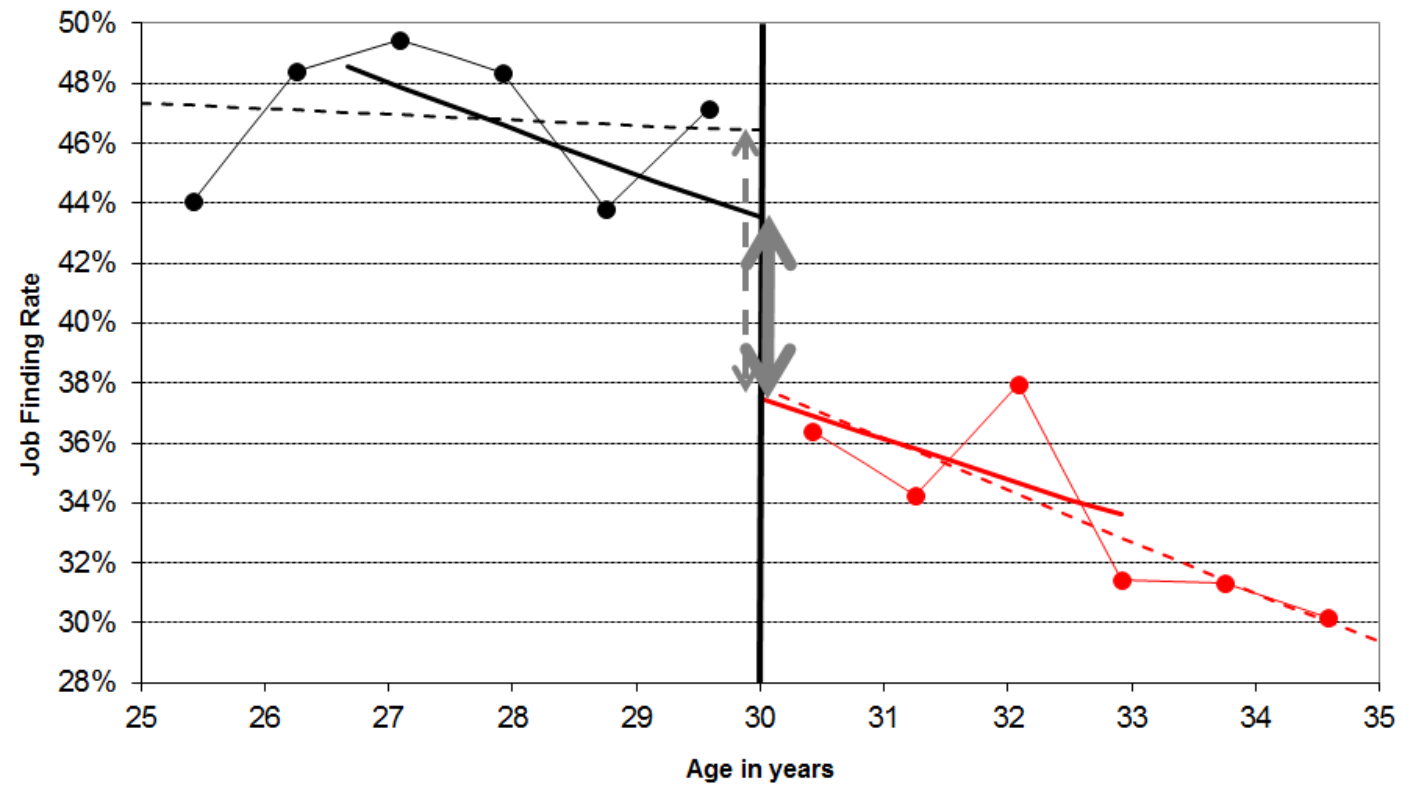

Note: The dashed (solid) straight lines depict the linear spline estimated within an age window of 5 years (40 months) on either side of the discontinuity. The vertical double-headed arrows display the coressponding sizes of the intention-to-treat effects eight months after notification.

As observed in many studies, the job finding rate is observed to decline with age, at least from about 27 years. At 30 years the job finding rate falls sharply. This is evidence that the notification sent to the unemployed less than 30 years old speeds up the transition to

\footnotetext{
${ }^{13}$ We follow Lee and Lemieux (2010, p. 309) and test this formally by doubling the number of bins (i.e. setting the bandwidth to five months). We test whether the associated bin indicators are jointly significantly different from the initially chosen ones. The corresponding F-test cannot reject the null hypothesis at a significance level of $5.2 \%$. If we maintain a bandwidth of five months for the last 10 months of the age window (i.e. between 410 and 419 months), then the p-value of the F-test increases to $44.0 \%$.
} 
employment. The solid straight lines to the left and to the right of the discontinuity point at 30 depict the linear spline estimated on data within an age window of 80 months (40 months at either side of the discontinuity at 30 years) as chosen in our benchmark model. The vertical double-headed arrow between these lines at the discontinuity displays the size of the intention-to-treat effect eight months after the notification. The dashed straight lines show the linear spline estimated on the full age window of five years on either side of the discontinuity. Since these lines cannot capture the increasing relationship between the job finding rate and age between 25 and 27 years, its slope on the left-hand side of the cutoff point is underestimated and, hence, overestimates the effect (see the dashed double-headed arrow at the discontinuity). This is essentially why we restrict the analysis to the narrower window in the benchmark. We discuss this choice further in Subsection 5.1.2.

Table 2 reports the main results for the benchmark model. The column below $\alpha_{k}$ reports the predicted job finding rate of 30 year olds in the absence of a notification. One month after the counterfactual notification 9 percent have already found a job. In the subsequent 4 months the job finding rate increases on average by nearly 5 percentage points (pp) per month, bringing the cumulative job finding rate to $28.5 \%$ after five months. From then until the eighth month after the counterfactual notification, the job finding rate slows down slightly to 3 pp per month. After eight months $37.5 \%$ of the 30 year olds have found a job.

The columns below $\beta_{k}$ report the treatment effects of notification for those slightly below the age of 30. The one headed by "OLS" reports the "intention-to-treat" effects. As mentioned in Section 4, these are only slightly lower than the 2SLS estimates, which weight the OLS estimates by the fraction of effectively notified, thereby explicitly taking the "fuzzy" nature of the RDD into account.

The point estimates suggest that the nofication increases the job finding rate considerably. This increase seems to occur especially in the second and third month after notification. In the second month the job finding rate increases by $5 \mathrm{pp}$ and in the third by an additional 2 pp. Between the third and sixth month the notification does not seem to have any further impact. Finally, in the last two months the job finding rate increases by an additional $1.3 \mathrm{pp}$ to end up with a cumulative increase of $8.8 \mathrm{pp}$, which corresponds to a proportional effect of $23 \% 14$ Even if these effects are not precisely estimated, this last effect is significant at a $\mathrm{p}$-value of $5.9 \%$ and for the other effects from the third month onwards the $\mathrm{p}$-values are close to $10 \%$.

In view of the relatively lenient monitoring system in which interviews are conducted at a low frequency, the job search requirements are not precisely defined and a benefit sanction is not imposed in the case of non-compliance at the first interview, these important treatment effects may come as a surprise. However, this does not mean that we should expect that such a scheme would not have any noticeable effect on rational individuals who are completely

\footnotetext{
${ }^{14} 0.088 / 0.375=0.023$
} 
Table 2: The Effect of Monitoring on the Job Finding Rate

\begin{tabular}{|c|c|c|c|c|c|c|c|}
\hline \multirow[b]{2}{*}{ \# months since notification $(k)$} & \multirow[b]{2}{*}{$\alpha_{k}^{(a)}$} & \multirow[b]{2}{*}{ standard error } & \multicolumn{2}{|c|}{ OLS } & \multicolumn{3}{|c|}{$2 \mathrm{SLS}^{(\mathrm{c})}$} \\
\hline & & & $\beta_{k}^{(b)}$ & s.e. & $\beta_{k}^{(\mathrm{b})}$ & standard error & p-value \\
\hline 1 & $0.092^{* *}$ & 0.023 & -0.013 & 0.035 & -0.012 & 0.041 & 0.766 \\
\hline 2 & $0.148^{* *}$ & 0.025 & 0.043 & 0.037 & 0.051 & 0.043 & 0.236 \\
\hline 3 & $0.192^{* *}$ & 0.026 & 0.062 & 0.039 & 0.071 & 0.045 & 0.115 \\
\hline 4 & $0.245^{* *}$ & 0.027 & 0.062 & 0.040 & 0.072 & 0.045 & 0.115 \\
\hline 5 & $0.285^{* *}$ & 0.027 & 0.063 & 0.040 & 0.072 & 0.046 & 0.116 \\
\hline 6 & $0.313^{* *}$ & 0.028 & 0.066 & 0.040 & 0.075 & 0.046 & 0.102 \\
\hline 7 & $0.339^{* *}$ & 0.028 & $0.073^{*}$ & 0.041 & $0.083^{*}$ & 0.046 & 0.073 \\
\hline 8 & $0.375^{* *}$ & 0.028 & $0.078^{*}$ & 0.041 & $0.088^{*}$ & 0.046 & 0.059 \\
\hline Order of the polynomial & & & & 1 & & & \\
\hline Spline & & & & yes & & & \\
\hline Window width & & $40 \mathrm{mo}$ & on eithe & side of & $\operatorname{ars}(D s$ & $\pm 4 * 10)$ & \\
\hline Control variables & & & & yes & & & \\
\hline$\#$ individuals $=N$ & & & & 1,490 & & & \\
\hline
\end{tabular}

(a) The job finding rate for 30 year olds without notification.

(b) The effect of the notification on the job finding rate of 30 year olds.

(c) 2SLS weighs the OLS ("intention-to-treat") estimate of the treatment effect with the fraction below 30 years that is effectively notified. It explicitly takes the "fuzzy" nature of the RDD into account.

* Significant at the $10 \%$ level; ** Significant at the $5 \%$ level.

informed about the functioning of the monitoring scheme. Cockx et al. (2011) estimate on the same data ${ }^{15}$ a non-stationary structural job search model that takes the main features of the Belgian monitoring scheme into account and find that eight months after notification the job finding rate is about 2 pp higher than without monitoring. This lies within the $90 \%$ confidence interval of the RDD point estimate.

Cockx et al. (2011) show that the incentive to increase search effort depends on the difference between the expected welfare in the case of a positive and negative outcome and the extent to which the probability of a positive evaluation can be influenced by enhanced job search effort. Despite the imprecision of job search requirements, Cockx et al. (2011) find clear evidence that this probability significantly increases with job search effort. In Section 2.2 we have mentioned that, compared to other countries, the sanctions in the case of non-compliance are relatively important. However, since the unemployed discount the future and since sanctions are not yet imposed at the first interview, it is probably rather the relatively high reward in the case of a positive evaluation that drives most of the effect of monitoring on the job finding rate before the first interview. A positive evaluation at the first interview delays the subsequent monitoring interview by as much as 16 months, while in other countries the frequency of interviews often remains fortnightly or monthly. Cockx et al. (2011) label this front-loading of job search effort, because the enhanced job search effort induced by the reward needs to be traded-off against the reduced effort after the interview.

The fact that the reported RDD estimates of the treatment effect are much higher than those estimated within a structural search model can be a consequence of their imprecision.

\footnotetext{
${ }^{15}$ Cohabitants who do not earn a flat rate benefit are excluded in their analysis.
} 
Another explanation could be that an important fraction of the notified long-term unemployed was not sufficiently literate (the notification was not transmitted in a face-to-face interview, but in a letter) to fully understand that non-compliance is sanctioned only after two negative evaluations and not earlier than one year after receipt of the notification. This interpretation is supported by the fierce criticism in the media in 2004 by trade-unions and other pressure groups that the new scheme would "hunt down" the unemployed. This could indeed have enhanced the perception that monitoring was very strict and the threat of a sanction very high, which may therefore have triggered an overreaction of some individuals who were not well informed about the monitoring procedure. This is also consistent with the time profile of the effect which suggests that the bulk of the effect is realized within the first three months after receipt of the notification.

Finally, note that monitoring in Belgium is targeted on long-term unemployed. For this group monitoring may be more effective than for short-term unemployed, since informal job search channels may have "dried up",16 so that there may be less scope for substitution between formal and informal search.

\subsubsection{Sensitivity Analysis}

In Table 3 we display how the treatment effect varies with the polynomial (spline) specification up to a second degree for sub-samples selected within an increasingly narrow age window around the cutoff point. All regressions include the explanatory variables mentioned in Table 1. In line with the bandwidth choice of the graphical analysis, we consider 6 discontinuity samples: $D S \pm 1 * 10-D S \pm 6 * 10$. The discontinuity sample $D S \pm 1 * 10$ consists of the treated within the age bracket $[350,360)$ months and the control group in the bracket $[360,369)$ (360 months $=30$ years). The other discontinuity samples are defined accordingly.

Table 3: The Intention-to-Treat Effect on the Job Finding Rate Eight Months after Notification $\left(\beta_{8}\right)$ for Various Windows and Polynomials

\begin{tabular}{lcccccc} 
Window width & $D S \pm 6 * 10$ & $D S \pm 5 * 10$ & $D S \pm 4 * 10$ & $D S \pm 3 * 10$ & $D S \pm 2 * 10$ & $D S \pm 1 * 10$ \\
\hline Polynom. order & & & & & & \\
Zero & $0.122^{* *}(0.020)$ & $0.120^{* *}(0.022)$ & $0.103^{* *}(0.025)$ & $0.083^{* *}(0.028)$ & $0.095^{* *}(0.035)$ & $0.109^{* *}(0.050)$ \\
One & $0.097^{* *}(0.033)$ & $0.090^{* *}(0.036)$ & $0.077^{*}(0.041)$ & $0.090^{* *}(0.047)$ & $0.118^{* *}(0.059)$ & $0.155^{* *}(0.086)$ \\
One spline & $0.098^{* *}(0.033)$ & $0.091^{* *}(0.036)$ & $\mathbf{0 . 0 7 8}^{*}(0.041)$ & $0.089^{*}(0.048)$ & $0.120^{* *}(0.059)$ & $0.156^{*}(0.087)$ \\
Two & $0.097^{* *}(0.033)$ & $0.091^{* *}(0.036)$ & $0.077^{*}(0.041)$ & $0.090^{* *}(0.047)$ & $0.117^{* *}(0.059)$ & $0.155^{*}(0.086)$ \\
Two spline & $0.104^{* *}(0.048)$ & $0.107^{* *}(0.053)$ & $0.125^{* *}(0.059)$ & $0.173^{* *}(0.069)$ & $0.177^{* *}(0.087)$ & $0.296^{* *}(0.136)$ \\
\hline \multirow{2}{*}{ \# indiv. = N } & 2,240 & 1,895 & 1,490 & 1.119 & 737 & 378
\end{tabular}

Standard errors in parentheses. In bold the benchmark estimate.

* Significant at the $10 \%$ level; ** Significant at the $5 \%$ level.

Observe that for the benchmark window $(D S \pm 4 * 10)$ with a linear, quadratic or linear

\footnotetext{
${ }^{16}$ See van den Berg and van der Klaauw (2006, p. 928), Calvo-Armengol and Jackson (2004) and Ioannides and Datcher Loury (2004, p. 1069-1071) for discussion on the "drying up" of informal job search channels over the course of the unemployment spell.
} 
spline specification of the polynomial the treatment effects are the most conservative ones of those reported in Table 3. This can be explained as follows. First, since from the graphical analysis we could deduce that the job finding rate decreases with age both to the left and to the right of the discontinuity, we expect that the specifications without a polynomial in age over estimate the treatment effect. We indeed find that for the three widest windows ( $D S \pm 4 * 10-D S \pm 6 * 10$ ) the estimated effects with the linear (spline) and quadratic polynomial are smaller than those without it. For the narrower windows $(D S \pm 1 * 10-D S \pm 3 * 10)$ this relation reverses, however. This is induced by the positive relationship between the outcome and age between 29 and 30, and between 31 and 32 years (see Figure2), which is captured by the polynomial if the data are restricted to these narrower windows, and reinforces therefore the estimated treatment effects as compared to those in the wider windows. Since in the literature it is generally found that the relationship between the job finding rate and age is negative, we believe that the observed positive relationship in the data is idiosyncratic and likely to bias the treatment effect upwards. Moreover, as already discussed in the previous subsection, following the same reasoning and illustrated by the dashed lines in Figure 2 the positive relation between the job finding rate and age between 25 and 27 years biases the effect in the same direction.

To conclude, from these arguments, since we believe that the true relationship between the job finding rate and age must be negative, the treatment effects estimated on the basis of a linear spline on the window that excludes the two widest age intervals ( $D S \pm 4 * 10)$ yield the most credible estimates of the treatment effect.

\subsubsection{Validity Tests}

In this subsection, we test for the validity of the RDD. We (i) consider a falsification test for alternative discontinuity points; (ii) check for the presence of a placebo treatment effect in the year prior to the reform; and (iii) test for precise manipulation of the RDD.

We implement the falsification test as proposed by Lee and Lemieux (2010, p. 326-27) by examining whether there are unexpected discontinuities in the regression function in other months. For this purpose, we add to the benchmark model ( $D S \pm 4 * 10$ ) with a linear spline indicator variables for each 10 months ${ }^{17}$ and we interact each of these variables with the time since notification $(k=1,2, \ldots 8)$. As such $6 \times 8=48$ additional parameters were estimated. The falsification test consists of testing whether these additional parameters are jointly different from zero. Note, since we specified a common polynomial in age for all $k$, the test does not only reject if there are unexpected discontinuities, but also if the polynomial is specific for certain $k$. However, we cannot reject the null (p-value $=0.418$ ). Since we expect the treatment effect to increase with $k$, we also tested whether only the interactions with the

\footnotetext{
${ }^{17}$ Note that the first indicator variable to the left and the right cannot be separately identified from the linear spline. We add therefore $3 \times 2=6$ indicator variables for the $D S \pm 4 * 10$ sample.
} 
indicators at $k=8$ were jointly significant. Again the null cannot be rejected ( $\mathrm{p}$-value $=$ 0.506).

Second, we estimated the effect of a placebo treatment on a sample of unemployed workers aged between 25 and 34 years old to whom a notification would have been sent if the monitoring scheme had been in place in 2003. The estimated intention-to-treat effect for the benchmark model ( $D S \pm 4 * 10$ ) is -0.2 percentage points with a standard error of $3.8 \mathrm{pp}$. Moreover, no treatment effect is significantly different from zero in a sensitivity analysis (not reported) similar to the one displayed in Table 2.

The RDD approach is only valid to the extent that individuals cannot alter their behavior - "manipulate the forcing variable" - to avoid (or to benefit from) the treatment, i.e. "to precisely "sort" around the discontinuity threshold" (Lee, 2008; Lee and Lemieux, 2010). In this study the forcing variable, age, cannot be manipulated directly, but indirectly, since assignment to the treatment is not solely based on age, but also on being a benefit claimant for 13 months or more. This unemployment duration can be manipulated if the unemployed workers anticipate the dispatch of the notification and leave unemployment even before the notification. Note, however, as stressed by Lee (2008), that this manipulation invalidates the RDD only to the extent that workers have a precise control over exit from unemployment. For instance, if anticipation implies increased job search, this need not invalidate the RDD, since the outcome of the job search process is random, so that the worker cannot avoid the notification with certainty. It would be more problematic if the worker, in anticipation of the notification, decided to decline her entitlement to UB. However, it is unlikely that a written notification raises the perceived marginal cost to that extent. Notice, in addition, in the case of temporary interruptions in the payment of UB, which applies to a substantial fraction of the sampled individuals (see the fraction with recent work experience in Table 1), it may be difficult to anticipate the exact moment at which the notification arrives, because the calculation of this moment is rather complex (see Section 3.1). Nevertheless, we test for the presence of this kind of precise manipulation.

We implement three tests. First, since the sample is selected at the end of the second month prior to notification (cf. Section 3.1), we can verify by RDD whether workers slightly below the age of 30 years are more likely to find a job one month before notification than workers slightly older than 30. In Figure 3 we present the graphical analysis of this effect. The evolution of the job finding rate over the age window is quite erratic. The dashed lines represent a linear spline specification for the $D S \pm 4 * 10$ sample. Since within this age window the job finding rate sharply increases with age both at the left- and the right-hand side of the discontinuity, the treatment effect for this benchmark is higher than for other bandwidths and polynomial specifications. The point estimate is equal to $2.1 \mathrm{pp}$ with a standard error equal to $1.3 \mathrm{pp}$. This is, however, the only specification for which the effect is significant at the $10 \%$ level. For instance, if we estimate the effect with a linear spline on the widest age 
window ( $D S \pm 6 * 10$ ), the relationship between the job finding rate and age again becomes negative as expected (see the solid lines in Figure 3) and the point estimate of the treatment effect is then equal to $0.7 \mathrm{pp}$ with a standard error equal to $1.1 \mathrm{pp}$. We therefore conclude that the notification is not anticipated.

Figure 3: Discontinuity of the Job Finding Rate One Month before Notification

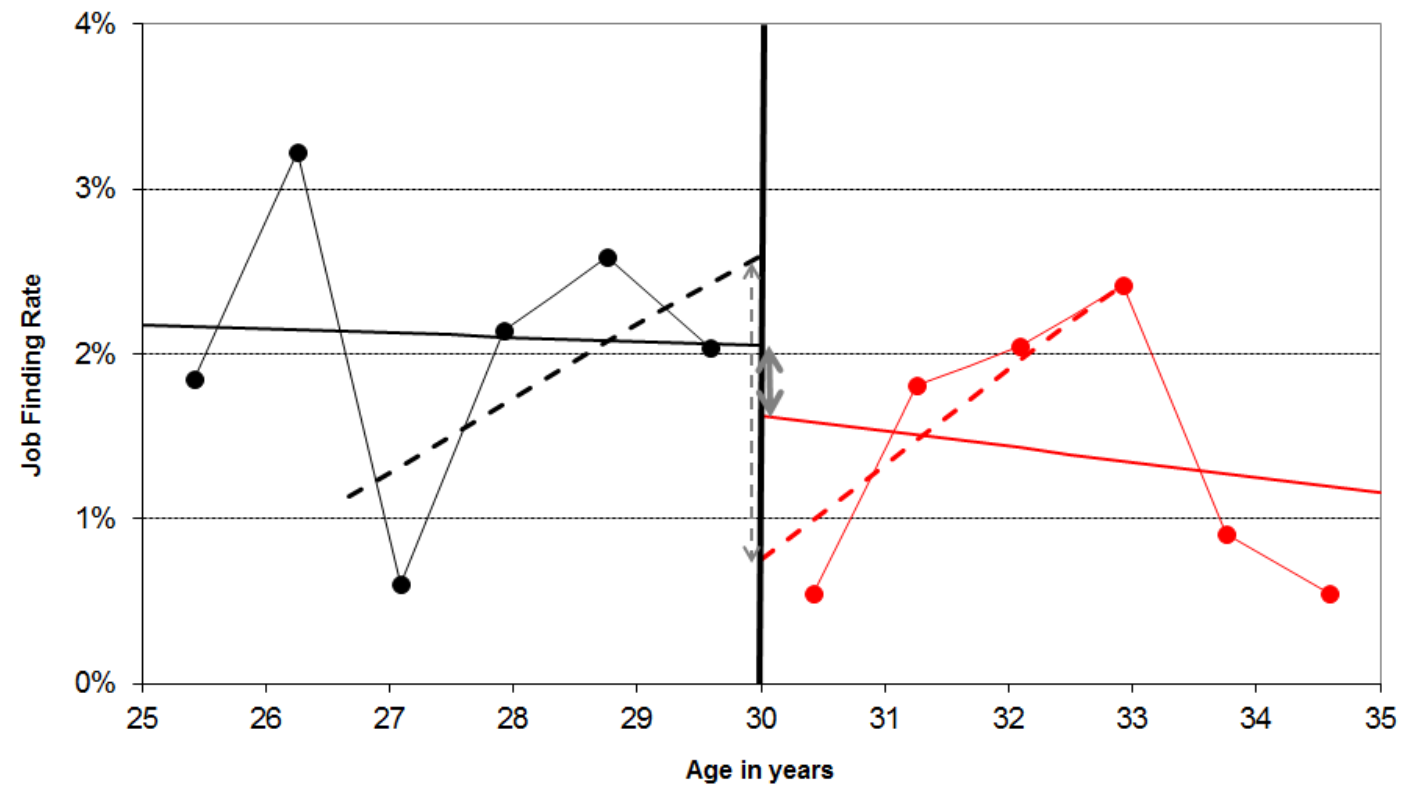

Note: The dashed (solid) straight lines depict the linear spline estimated within an age window of 5 years (40 months) on either side of the discontinuity. The vertical double-headed arrows display the coressponding sizes of the intention-to-treat effects one month before notification.

Second, we test whether the 18 predetermined characteristics (reported in Table 1) are smooth around the cutoff age. To do so, we follow the suggestion of Lee and Lemieux (2010) to estimate for the widest window size all 18 regression equations with a common linear spline jointly in a Seemingly Unrelated Regression (SUR) and test for the joint significance of discontinuities at the cutoff point for the $D S \pm 4 * 10$ sample. Even if one variable (lower secondary school) is individually significant at the $5 \%$ level, the absence of discontinuities cannot jointly be rejected at a p-value of $16 \%(\mathrm{~F}(17,1489)=1.34)$. Finally, we test whether the density of the forcing variable is continuous around the threshold (McCrary, 2008). This density test is displayed graphically in the two panels of Figure 4 . From this figure, but also from the formal tests (not reported), there is no evidence of any discontinuity. 
Figure 4: Graphical Density Test of the Forcing Variable

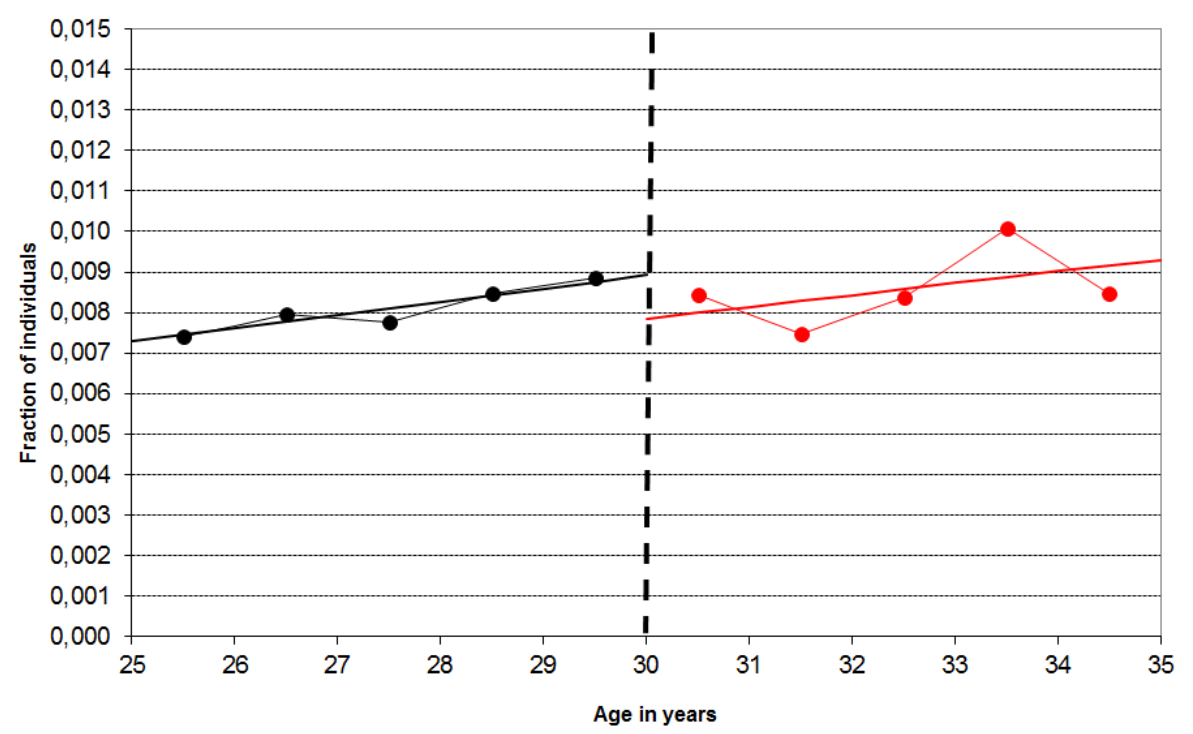

\subsection{Transitions into Training and out of the Labor Force}

Figure 5 displays the effects of monitoring on transition into training and out of the labor force ${ }^{18}$ From this Figure we deduce that, in anticipation of the first evaluation of job search effort, participation in training increases somewhat, while transition out of the labor force is not at all affected. According to a linear spline specification for the $D S \pm 4 * 10$ sample (the benchmark) the notification increased participation in training by $6.5 \mathrm{pp}$ (2SLS) with a p-value equal to $9.7 \%$. For other age windows (not reported) the estimated effects are lower and never significant at the $10 \%$ level. For instance, for the widest age window the point estimate falls to $3.9 \mathrm{pp}(\mathrm{p}$-value $=22.1 \%)$. By contrast, monitoring does not affect the transition out of the labor force. The treatment effect in the benchmark model is $1.0 \mathrm{pp}$ and highly non-significant. In a sensitivity analysis (available on request) the effect is always very small and never significantly different from zero. Finally note that both the placebo test on the sample selected in 2003 and the test regarding the anticipation of the notification cannot be rejected for either outcome variables. 19

These findings are in line with expectations. First, Manning (2009) and Petrongolo (2009) show that the imposition of stricter job search requirements does not enhance search incentives for all workers, since, if behavior is followed-up too closely, workers may find it too onerous to continue claiming benefits and may withdraw from the labor force instead. Here,

\footnotetext{
${ }^{18}$ The data enebled us to distinguish between claimants of sickness insurance benefits and other forms of inactivity. A separate analysis of these states did not, however, reveal any differential effects (Cockx and Dejemeppe, 2010).

${ }^{19}$ These results are available on request.
} 
Figure 5: Discontinuity of the Transition to Training and out of the Labor Force Eight Months After Notification
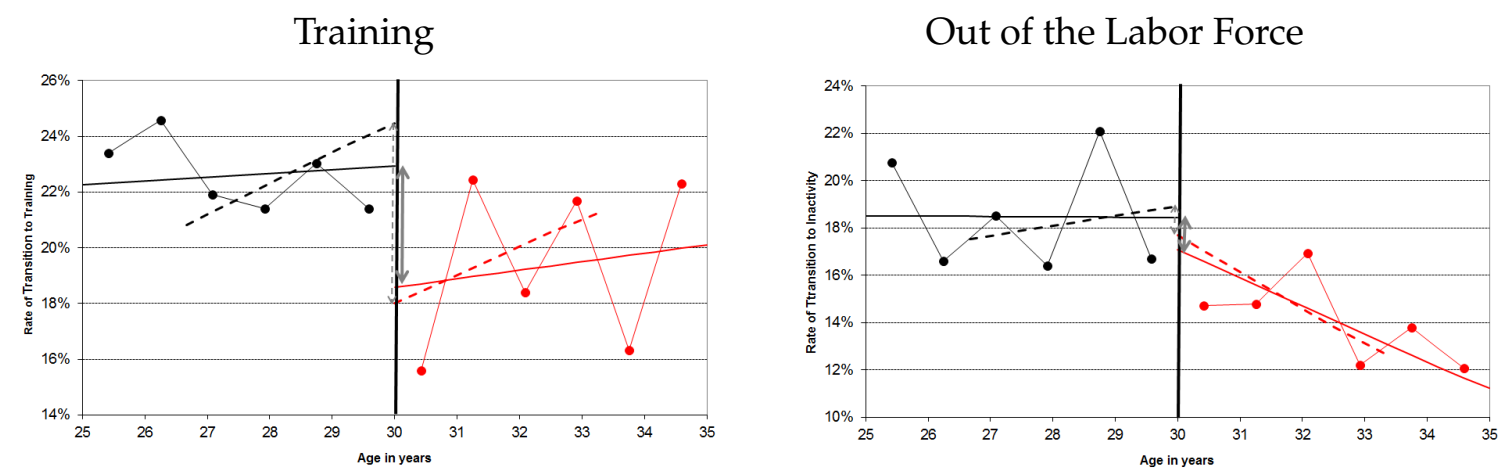

Note: The dashed (solid) straight lines depict the linear spline estimated within an age window of 5 years (40 months) on either side of the discontinuity. The vertical double-headed arrows display the coressponding sizes of the intention-to-treat effects eight months after notification.

since it is costly to forgo UB, it is unlikely that such withdrawals occur before the moment at which one risks a benefit sanction, i.e. not before the second monitoring interview. The insignificant effect on withdrawal from the labor force is consistent with this hypothesis.

Second, the notification letter states that the person concerned should contact the regional PES if she has not yet been individually counseled before and that she must participate in any action proposed by the regional PES. However, in Flanders the regional PES should already have systematically counseled those unemployed for more than nine months (see Section 2.1). For many workers there might therefore already have been a relatively recent contact with the PES, which may explain why the effect of the notification on training participation is not so strong as its effect on the job finding rate.

Even if the impact of monitoring on training is not so strong, one may nevertheless question whether training is not the main pathway through which monitoring works. If so, the effect of monitoring should be much lower if indirect transitions to employment after participation in training (or inactivity) are excluded. Eight months after notification the direct transition rate to employment is according the benchmark model $6.1 \mathrm{pp}$ (standard error $=$ $4.6 \mathrm{pp}$ ) higher than in the absence of notification. Compare this to the point estimate of 8.8 pp reported in Table 2. This suggests that roughly 30\% of the total impact on the job finding rate could be induced by enhanced participation in training caused by the notification.

\section{Conclusion}

This paper studied the impact of an important reform in Belgium which introduced for the first time job search requirements into the UB scheme. More specifically, it evaluated the effect on various outcome variables (employment, participation in training and labor force 
withdrawal) of a notification announcing that job search effort will be retrospectively monitored at least eight months later.

Eight months after this notification and prior to the first evaluation of job search effort the likelihood of a transition to employment is nearly 9 pp higher than in the absence of the reform. This finding is robust, but not precisely estimated. In view of the relatively lenient monitoring system in which interviews are conducted at a low frequency, the job search requirements are not clearly defined and a benefit sanction is not imposed in the case of non-compliance at the first interview, this high treatment effect may come as a surprise. Nevertheless, this does not mean that one should expect no effect of this notification. Based on a non-stationary job search model that takes the main features of the Belgian monitoring scheme into account, Cockx et al. (2011) find that an increase of 2 pp is consistent with the rational behavior of individuals who are completely informed about the functioning of the monitoring scheme. They argue that the relatively high reward in the case of a positive evaluation drives most of this effect. This is because a positive evaluation at the first interview delays the subsequent monitoring interview by as much as 16 months. Cockx et al. (2011) label this front-loading of job search effort, because the enhanced job search effort induced by the reward must be traded-off against the reduced effort after the interview.

The fact that the RDD point estimates are much higher than those estimated within a structural search model can be explained by their imprecision, but can also follow from an incomplete understanding of the monitoring procedure upon receipt of the written notification. Since the monitoring is targeted at long-term unemployed, a non-negligible share of the notified individuals may not be sufficiently literate to fully understand that non-compliance is sanctioned only after two negative evaluations and not earlier than one year after receipt of the notification. The fierce criticism in the media in 2004 by trade-unions and other pressure groups that the new scheme would "hunt down" the unemployed may have had a larger impact on the behavior of this group. This could indeed have enhanced the perception that monitoring was very strict and the threat of a sanction very high, which may therefore have triggered an overreaction of these individuals.

The notification also enhanced the transition into training, but not so much as the transition into employment. According to the benchmark model the participation rate increased by $6.5 \mathrm{pp}$, but for other specifications the effect was found to be lower and not significantly different from zero. This is because many of the unemployed were relatively recently counseled at the regional Public Employment Office, so that if training is more appropriate than job search, it would have started earlier, before the (potential) notification. Nevertheless, we found evidence that the enhanced training participation induced by monitoring could have been a pathway to employment for about one third of the increase in the job finding rate: If indirect transitions to employment via training (or inactivity) are excluded, the treatment effect after eight months falls from $8.8 \mathrm{pp}$ to $6.1 \mathrm{pp}$. 
It is unlikely that the unemployed would, in response to the job search requirements, withdraw from the labor force before the moment at which they risk a benefit sanction. Since this moment occurs no earlier than four months after the first evaluation of job search effort, the finding that impact on the transition to inactivity is close to zero and insignificant is consistent with this hypothesis.

The finding that monitoring without an immediate risk of a sanction can enhance the job finding rate substantially without stimulating the withdrawal from the labor force is important, since it demonstrates that this outcome can be realized without an immediate income loss for benefit recipients. However, this positive outcome comes at the expense of social costs that are realized ex-post and not analyzed in this research. Some benefit claimants will be sanctioned if they persist in non-complying. Moreover, the front-loading of job search effort prior to the interview comes at an expense of a decline in job search effort ex-post, in the case of a positive evaluation. Whether it is socially optimal to design monitoring schemes with such features depends crucially on the individual and social discount rate and remains to be studied.

Finally, our explanation for the magnitude of the treatment effect suggests that it is more the perceived than the effective strictness that determines whether monitoring works. Reaching a better understanding of how these perceptions are formed is therefore an interesting research avenue.

\section{Acknowledgements}

We acknowledge funding by the Belgian Federal Administration Science Policy within the program "Society and Future" (contract no. TA/00/11) and the Interuniversity Poles of Attraction [Contract No. P6/P7]. We thank Bruno Crépon, Anne Defourny, Marc Gurgand, Michael Lechner, Thierry Magnac, William Parienté, Matteo Picchio, Jeffrey Smith, Sébastien Van Bellegem, Bruno van der Linden, three anonymous referees and the editor for discussions and comments.

\section{References}

Ashenfelter, O., D. Ashmore, and O. Deschênes (2005) ‘Do Unemployment Insurance Recipients Actively Seek Work? Evidence from Randomized Trials in Four U.S. States.' Journal of Econometrics 125(1-2), 53-75

Battistin, E., and E. Rettore (2008) 'Ineligibles and Eligible Non-Participants as a Double Comparison Group in Regression Discontinuity Designs.' Journal of Econometrics $142,715-730$ 
Boone, J., P. Fredriksson, B. Holmlund, and J. van Ours (2007) 'Optimal Unemployment Insurance with Monitoring and Sanctions.' The Economic Journal 117(518), 399-421

Borland, J., and Y.-P. Tseng (2007) 'Does a Minimum Job Search Requirement Reduce the Time Spent on Unemployment? Evidence from the Job Seekers Diary in Australia.' Industrial and Labor Relations Review 60(3), 357-378

Calvo-Armengol, A., and M. O. Jackson (2004) 'The Effects of Social Networks on Employment and Inequality.' American Economic Review 94(3), 426-454

Cockx, B., and J. Ries (2004) 'The Exhaustion of Unemployment Benefits in Belgium. Does it Enhance the Probability of Employment?' Discussion Paper No. 1177, Bonn: IZA

Cockx, B., and M. Dejemeppe (2007) 'Is the Notification of Monitoring a Threat to the Unemployed? A Regression Discontinuity Approach.' IZA discussion paper 2854

_ (2010) 'The Threat of Monitoring Job Search. A Discontinuity Design.' IZA discussion paper 5337

Cockx, B., M. Dejemeppe, A. Launov, and B. Van der Linden (2011) 'Monitoring, Sanctions and Front-Loading of Job Search in a Non-Stationary Model.' IZA discussion paper 6181

Dolton, P., and D. O'Neill (1996) 'Unemployment Duration and the Restart Effect: Some Experimental Evidence.' The Economic Journal 106(435), 387-400

_ (2002) 'The Long-Run Effects of Unemployment Monitoring and Work-Search Programs: Experimental Evidence from the United Kingdom.' Journal of Labor Economics 20(2), 381-403

Gorter, C., and G.R.J. Kalb (1996) 'Estimating the Effect of Counseling and Monitoring the Unemployed Using a Job Search Model.' Journal of Human Resources 31, 590-610

Imbens, G. W., and T. Lemieux (2008) 'Regression Discontinuity Designs: A Guide to Practice.' Journal of Econometrics 142, 615-635

Ioannides, Y., and L. Datcher Loury (2004) 'Job Information Networks, Neighborhood Effects, and Inequality.' Journal of Economic Literature XLII, 1056-1093

Klepinger, D. H., T.R. Johnson, and J.M. Joesch (2002) 'Effects of Unemployment Insurance Work Search Requirements: The Maryland Experiment.' Industrial and Labor Relations Review 56(1), 3-22

Klepinger, D. H., T.R. Johnson, J.M. Joesch, and J.M. Benus (1997) Evaluation of the Maryland Unemployment Insurance Work Search Demonstration (Seattle and Bethesda: Batelle Memorial Instiute and Abt Associates Inc.) 
Lalive, R., J. van Ours, and J. Zweimuller (2006) 'How Changes in Financial Incentives Affect the Duration of Unemployment.' The Review of Economic Studies 73, 1009-1038

Lee, D. S. (2008) 'Randomized Experiments from Non-random Selection in U.S. House Elections.' Journal of Econometrics 142(2), 675-697

Lee, D. S., and T. Lemieux (2010) 'Regression Discontinuity Designs in Economics.' Journal of Economic Literature 48(2), 281-355

Manning, A. (2009) 'You Can't Always Get What You Want: The Impact of the UK Jobseeker's Allowance.' Labour Economics 16(3), 239-250

McCrary, J. (2008) 'Manipulation of the Running Variable in the Regression Discontinuity Design: A Density Test.' Journal of Econometrics 142, 698-714

McVicar, D. (2008) 'Job Search Monitoring Intensity, Unemployment Exit and Job Entry: Quasi-Experimental Evidence from the UK.' Labour Economics 15, 1451-1468

Meyer, B. D. (1995) 'Lessons from the U.S. Unemployment Insurance Experiments.' Journal of Economic Literature 33, 91-131

OECD (2007) Employment Outlook (Paris: OECD)

Petrongolo, B. (2009) 'The Long-Term Effects of Job Search Requirements: Evidence from the UK JSA Reform.' Journal of Public Economics 93, 1234-1253

van den Berg, G. J., and B. van der Klaauw (2006) 'Counseling and Monitoring of Unemployed Workers: Theory and Evidence from a Controlled Social Experiment.' International Economic Review 47(3), 895-936 